УДК 550.42; 550.47

\title{
ГЕОХИМИЧЕСКИЕ ОСОБЕННОСТИ ДОННЫХ ОСАДКОВ В ОБЛАСТЯХ РАЗГРУЗКИ МЕТАН-СОДЕРЖАЩИХ ФЛЮИДОВ НА ВНЕШНЕМ ШЕЛЬФЕ МОРЯ ЛАПТЕВЫХ
}

\author{
Рубан Алексей Сергеевич1, \\ Рубан Алекс
}

\author{
Рудмин Максим Андреевич1, \\ rudminma@tpu.ru
}
Мазуров Алексей Карпович ${ }^{1}$, akm@tpu.ru

Милевский Яков Вадимович1,
yvm16@tpu.ru

\author{
Семилетов Игорь Петрович2,1, \\ ipsemiletov@alaska.edu
}

\author{
Гершелис Елена Владимировна 1 \\ elenapanova@tpu.ru
}

Дударев Олег Викторович2, dudarev@poi.dvo.ru

\footnotetext{
1 Национальный исследовательский Томский политехнический университет, Россия, 634050, г. Томск, пр. Ленина, 30.

2 Тихоокеанский океанологический институт им. В.И. Ильичева ДВО РАН, Россия, 690041, г. Владивосток, ул. Балтийская, 43.
}

\begin{abstract}
Актуальность. Характерной особенностью шельфра моря Лаптевых является наличие участков массированной разгрузки метан-содержащих фрлюидов с поверхности морского дна в водную толщу - метановых сипов. Ключевыми биогеохимическими процессами, протекающими при миграции метана через осадочную среду, являются анаэробное окисление метана и бактериальная сульфратредукция. Активность этих процессов приводит к изменению окислительно-восстановительных условий седиментации, что влияет на биогеохимические циклы ряда редокс-чувствительных элементов.

Цель: изучение влияния просачивающихся метан-содержащих фрюидов на геохимические циклы железа, углерода и некоторых редокс-чувствительных элементов.

Объект. Были проанализированы данные о концентрациях углерода, железа, и ряда редокс-чувствительных элементов (Мn, $\mathrm{Co}, \mathrm{Ni}, \mathrm{Cu}, \mathrm{Zn}, \mathrm{Cr}, \mathrm{Ba}, \mathrm{Mo}, \mathrm{U})$ в трех кернах донных осадков, отобранных на внешнем шельфее моря Лаптевых. Два из трех кернов получены на участках с зарегистрированной разгрузкой метан-содержащих фрлюидов и рассматривались в качестве осадков, подверженных анаэробному окислению метана.

Meтоды: пиролиз (Rock-Eval 6 Turbo, Vinci Technologies), рентеенофрлуоресцентный анализ (HORIBA X-Ray Analytical Microscope XGT 7200), масс-спектрометрия с индуктивно-связанной плазмой (ИСП-MC, ELAN DRC-e).

Результаты. Содержания TOC и Fe в донных осадках не отражают влияния анаэробного окисления на их геохимические циклы и контролируются спецификой пространственного распределения потоков осадочного материала. Во всех изученных кернах отмечаются повышенные концентрации $\mathrm{Mn}$, приуроченные к поверхностному горизонту осадков. На участках разгрузки метана поверхностный слой донных осадков характеризуется обогащением Mo, Ni и Cr. Избирательное обогащения поверхностного слоя осадков некоторыми редокс-чувствительными элементами может быть вызвано миграцией метансодержащих фрлюидов, способствующих переносу элементов в растворенной форме из более глубоких горизонтов. Сорбция этих элементов органическим веществом и окислами/гидрокислами Fe-Mn, по-видимому, является ключевым механизмом, контролирующим осаждение Mo, $\mathrm{Ni}$ и $\mathrm{Cr}$.
\end{abstract}

\section{Ключевые слова:}

Геохимия, метановые сипы, анаэробное окисление метана, море Лаптевых.

\section{Введение}

Шельф моря Лаптевых, наряду с шельфами других морей Восточной Арктики, является одним из крупнейших и мелководных в Мировом океане. В то же время степень изученности данного района крайне низкая ввиду его труднодоступности и непродолжительного безледного периода (около 2-3 месяцев в году) [1]. Зарегистрированные в последние десятилетия изменения климата, наиболее заметно проявляющиеся в арктическом регионе [2], несомненно, отражаются на направленности осадочных процессов. В первую очередь это выражается в изменении объема и состава поставляемого в бассейн седиментации осадочного материала, его пространственном распределении в акватории, скоростях осадконакопления, активизации различных биохимических процессов и пр. Пе- речисленные выше факторы могут способствовать изменению окислительно-восстановительных условий на границе «донные осадки - морская вода» [3].

Кроме того, важной особенностью шельфа моря Лаптевых является наличие участков массированной разгрузки метан-содержащих флюидов с поверхности морского дна в водную толщу - метановых сипов (англ. cold methane seep). Последние являются широко распространенным явлением в Мировом океане, проявляющимся в различных морских условиях как на пассивных, так и на активных континентальных окраинах [4, 5 и ссылки в них]. При столкновении восходящего потока метана и нисходящего диффузионного потока сульфата из морской воды создается сульфат-метановая транзитная зона (СМТ3), положение которой в разрезе контролируется интенсивностью потока метан-содержащего флюида. Доминиру- 
ющими биогеохимическими процессами в СМТЗ являются анаэробное окисление метана (АОМ) и бактериальная сульфатредукция, управляемые консорциумом анаэробных метанокисляющих архей и сульфатредуцирующих бактерий [6, 7]. При высоких флюидных потоках АОМ часто протекает в верхних горизонтах или даже непосредственно на границе донных осадков и морской воды [8]. Активность сульфатредуцирующих бактерий приводит к истощению сульфата не только в поровых, но и в придонных водах и, как следствие, способствует продуцированию сероводорода [9]. Это приводит к изменению окислительно-восстановительных условий седиментации, что влияет на биогеохимические циклы ряда редокс-чувствительных элементов (например, $\mathrm{Mn}, \mathrm{Mo}$, $\mathrm{U}, \mathrm{Ba}, \mathrm{Cd}$ и др.), поскольку их накопление в морских осадках контролируется в первую очередь концентрациями кислорода [10]. Поведение таких элементов как Мo, U, Ba, характеризующихся обогащением в аноксических условиях, детально изучено на примере метановых сипов различных акваторий Мирового океана, что отражено в многочисленных работах [9, 11-15]. Однако поведение других редоксчувствительных микроэлементов в донных осадках метановых сипов исследовано в значительно меньшей степени. Более того, опубликованные работы, посвященные геохимии «метановых» осадков в морях Северного Ледовитого океана, ограничиваются единичными работами [16]. При этом уровень актуальности данного вопроса с позиции климатических палеореконструкций, моделирования современных климатических изменений, а также геолого-разведочных работ на углеводородные полезные ископаемые в пределах Арктического шельфа продолжает стремительно расти.

В рамках данной работы было изучено поведение углерода, железа и некоторых редокс-чувствительных микроэлементов в донных осадках, отобранных на двух метановых участках и за их пределами. Целью исследования являлось изучение влияния просачивающихся метан-содержащих флюидов на геохимические циклы перечисленных выше элементов.

\section{Геологические условия}

По географическому положению и гидрологическим условиям море Лаптевых относится к типу материковых окраинных морей. Оно ограничено архипелагом Северная Земля и полуостровом Таймыр с запада и Новосибирскими островами с востока. Значительная часть моря представлена шельфом с глубинами не более 100 м. Основными источниками осадочного материла, поставляемого в море Лаптевых, являются речной сток (в первую очередь р. Лена, шлейф которой прослеживается на внешнем шельфе [17]) и продукты эрозии берегового ледового комплекса, скорость которой достигает 18 м/год [18]. Район исследований расположен в пределах внешнего шельфа моря Лаптевых на сочленение трех крупных структур - рифтовой системы моря Лаптевых, срединно-океанического хребта Гаккеля и Северного трансформного разлома (или Хатангско-Ломоносовской зоны разломов [19]). Основ- ными структурными элементами рифтовой системы моря Лаптевых являются протяженные грабены и разделяющие их поднятия - горсты [20].

В 2011 г. во время экспедиции на НИС «Академик М.А. Лаврентьев» в северной части моря Лаптевых впервые были обнаружены восходящие струи метансодержащих флюидов (между 76,5-77,5 с.ш. и 121132 в.д., глубина воды от 52 до 74 м). С помощью многоканального гидроакустического комплекса на

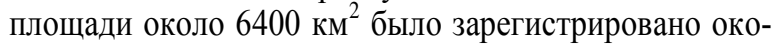
ло 700 отдельных метановых «факелов» [21]. Задокументированные концентрации растворенного метана в придонном горизонте водной толщи достигают 1511 нмоль/л при среднем значении 151 нмоль/л, что отражает перенасыщение на $23800 \%$ относительно атмосферных равновесных концентраций ( 4 нмоль/л [22]). Широко распространенные в этом районе разломы, которые представлены северо-западными взбросами и северо-восточными сдвигами с амплитудами смещения до 2 км [23, 24], могут служить подводящими каналами для миграции углеводородов из глубоких горизонтов [25]. Еще одним фактором, потенциально благоприятствующим восходящей миграции метан-содержащих флюидов, является деградация подводной вечной мерзлоты, которая подстилает Восточно-Сибирский арктический шельф. Миграция метана может происходить через сквозные талики, которые образуются под затопленными термокарстовыми озерами [26]. Кроме того, деградация подводной мерзлоты может способствовать продуцированию метана в талых отложениях [27].

\section{Фактический материал и методы}

Фактическим материалом для данного исследования послужили три керна поверхностных донных осадков, отобранных на внешнем шельфе моря Лаптевых (рис. 1). Керны АМК-6027 (длина 18 см) и АМК-6053 (длина 16 см) были получены в 73-м рейсе НИС «Академик Мстислав Келдыш» (2018 г.) с использованием коробчатого пробоотборника (бокскорера), позволяющего получать ненарушенную вырезку донных осадков в виде куба (рис. 2, $b$ ). После подъёма пробоотборника на палубу в полученную вырезку вдавливалась пластиковая труба внутренним диаметром 100 мм. Керн АМК-6948 (длина 14 см) был отобран в 82-м рейсе НИС «Академик Мстислав Келдыш» (2020 г.) с помощью мультикорера Octopus (рис. 2, a), позволяющего получать керны диаметром 95 мм (рис. 2, c). После отбора керны послойно разрезались на пробы с шагом 1 и 2 см, далее пробы упаковывались в пластиковые пакеты, замораживались и хранились при отрицательной температуре до начала лабораторных исследований. Глубина моря на станциях АМК6027, АМК-6053 и АМК-6948 составляла 64, 65 и 72 м.

Для проведения аналитических исследований пробы донных осадков размораживались, гомогенезировались и высушивались до постоянной массы. Далее высушенные пробы истирались в кольцевой мельнице (ROCKLABS Standard Ring Mill) в течение 2 минут при частоте вращения 700 об/мин до размера частиц $\sim 10$ мкм. 


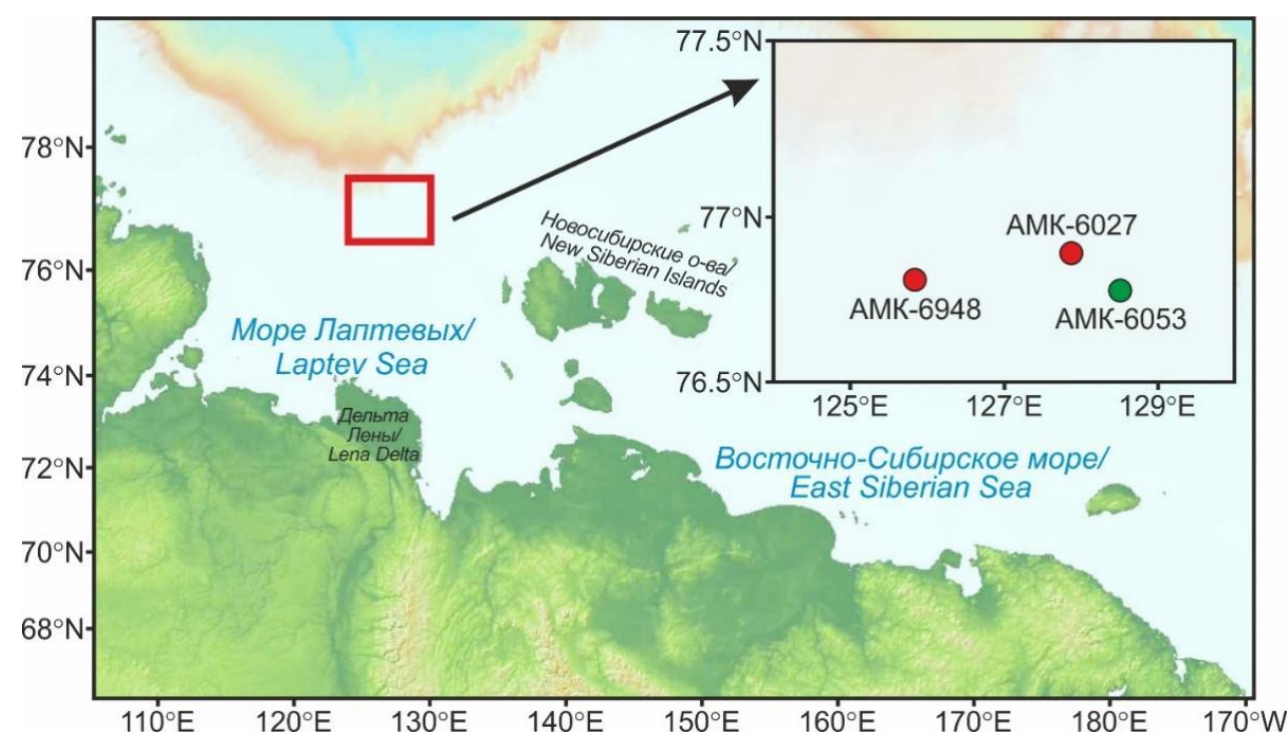

Рис. 1. Карта расположения станций отбора проб донных осадков в море Лаптевых (красным выделены станции, где была зарегистрирована разгрузка метана)

Fig. 1. Map of the sampling stations location for sediments in the Laptev Sea (the red circle symbol represents stations at which methane seeps were registered)

Определение содержаний общего органического и минерального углерода проводилось пиролитическим методом с использованием прибора Rock-Eval 6 Turbo компании Vinci Technologies (Франция). Силикатный анализ выполнялся на рентгенофлуоресцентном микроскопе HORIBA X-Ray Analytical Microscope XGT 7200. Для этого были изготовлены таблетки, спрессованные при давлении 25 МПа и прокаленные при температуре $900{ }^{\circ} \mathrm{C}$. Измерения проводились в 5 точках, равномерно распределенных по площади таблет- ки, а полученные значения усреднялись методом среднего арифметического. При анализе были заданы следующие параметры: напряжение рентгеновской трубки - 50 кВ, сила тока - 0,5 мА, время измерения 100 с, площадь луча 1,2 мм. Предел обнаружения основных оксидов - до 0,01\%. Содержания элементовпримесей определялись методом масс-спектрометрии с индуктивно-связанной плазмой (ИСП-МС). Исследования выполнялись с использованием ИСП-массспектрометра ELAN (модель DRC-е).

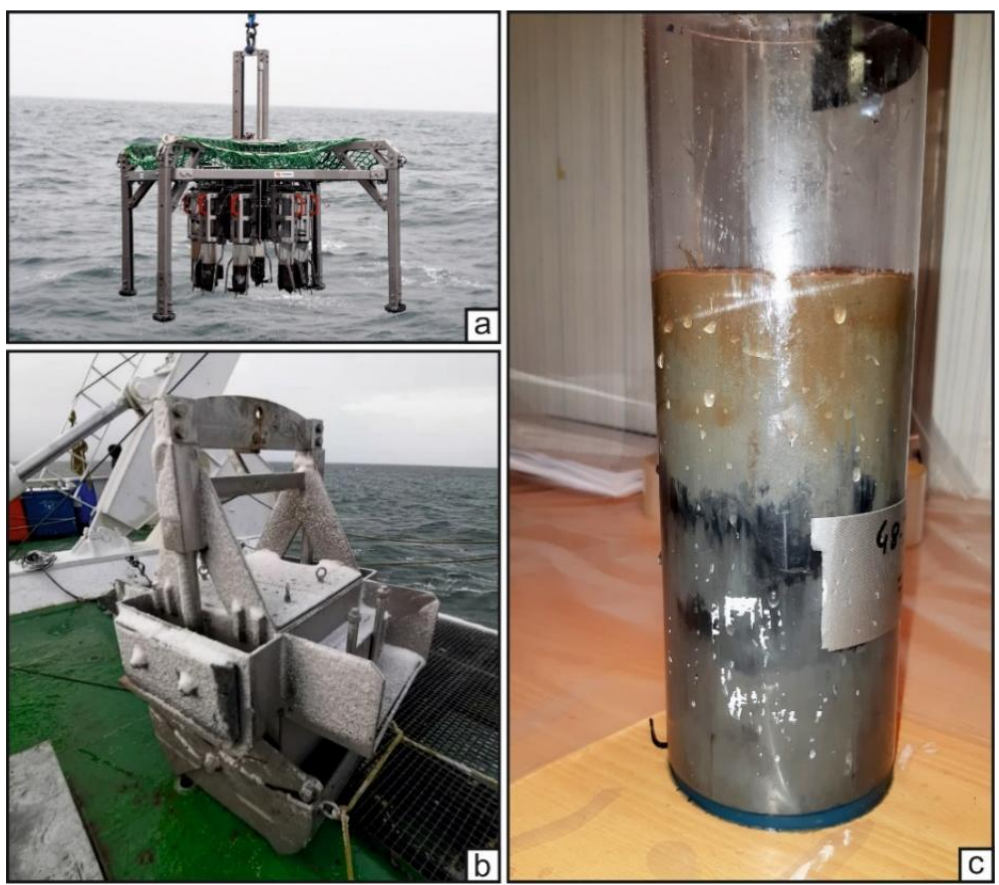

Рис. 2. Глубоководное оборудование, используемое для получения фактического материала: а) мультикорер Осtориs, b) коробчатый пробоотборник (бокскорер); с) пример керна донных осадков (АМК-6948), полученного с использование мультикорера

Fig. 2. Equipment used for sampling: a) Octopus multicorer; b) boxcorer; c) sediment core (AMK-6948) obtained using a multicorer 
Фактор обогащения (EF - enrichment factor) рассчитывался по формуле $\left.\mathrm{EF}_{\mathrm{X}}=\left[(\mathrm{X} / \mathrm{Al})_{\text {образец }} / \mathrm{X} / \mathrm{Al}\right)_{\text {кора }}\right]$, где $\mathrm{X}$ и $\mathrm{Al}$ представляют собой массовые концентрации X элемента и $\mathrm{Al}$ соответственно. Для расчета ЕF концентрации элементов были нормализованы на $\mathrm{Al}$. EF>1 указывает на аутигенное обогащение элемента относительно его среднего содержания в осадочных породах континентальной коры [28], тогда как EF>10 соответствует умеренной или сильной степени обогащения [8]

\section{Результаты}

Керны АМК-6027 и АМК-6948 были отобраны на участках разгрузки метан-содержащих флюидов, и в данной работе они рассматриваются как «метановые» донные осадки. На станции АМК-6053 не было зарегистрировано повышенных содержаний метана ни в донных осадках, ни в водной толще, следовательно, полученный здесь керн принят в качестве «фоновых» донных осадков.

Вертикальное распределение органического (TOC - total organic carbon) и минерального углерода
(TIC - total inorganic carbon) в кернах АМК-6027, АМК-6948 и АМК-6053 показано на рис. 3. Концентрации органического углерода в осадках на участках метановой разгрузки и в фоновых донных осадках изменяются в диапазонах от 0,32 до $0,93 \%$ и от 1,02 до $1,19 \%$ соответственно (табл. 1). Для метановых осадков характерно снижение концентраций ТОС с глубиной, в то время как для фоновых осадков подобного снижения не наблюдается. Максимальные содержания органического углерода во всех трех кернах приурочены к приповерхностному горизонту осадков. Содержания минерального углерода в «метановых» осадках варьируют в пределах от 0,08 до $0,23 \%$ (среднее $=0,14 \%$ и и увеличивается с глубиной. При этом максимальная концентрация ТIC отмечается в горизонтах 4-5 и 16-18 см (ниже границы «донные осадки - морская вода») керна АМК-6948 и керна АМК-6027 соответственно. Узкий диапазон, содержаний ТIC в фоновых осадках $(0,17 \ldots 0,21 \%$, среднее $0,19 \%)$, демонстрирует его достаточно низкую вертикальную изменчивость.
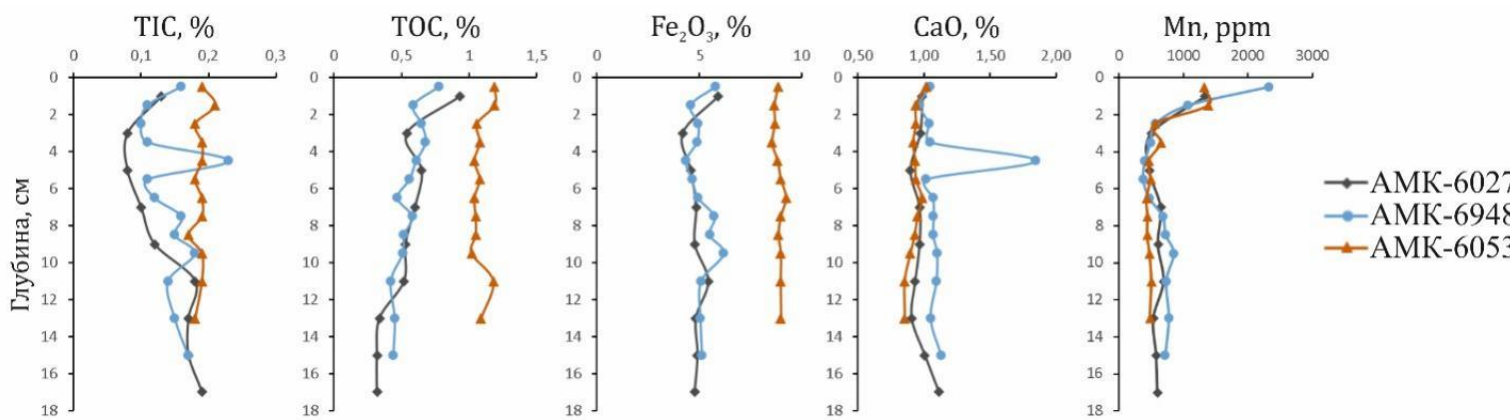

$\rightarrow$ AMK-6948

$\_\mathrm{AMK}-6053$

Pис. 3. Профили вертикального распределения концентраций ТIC, TOC, $\mathrm{Fe}_{2} \mathrm{O}_{3}, \mathrm{CaO}$ и $\mathrm{Mn}$ в кернах $\mathrm{AMK}-6027$, $A M K-6948$ u $A M K-6053$

Fig. 3. Vertical distributions of TIC, TOC, $\mathrm{Fe}_{2} \mathrm{O}_{3}, \mathrm{CaO}$ and $\mathrm{Mn}$ in cores $\mathrm{AMK}-6027, \mathrm{AMK}-6948$ and AMK-6053

Вертикальное распределение Мn показывает схожесть его поведения как в метановых, так и в фоновых осадках. Поверхностный слой (0-2 см) характеризуется примерно двух-трехкратным обогащением Мn относительно его среднего содержания в каждом из трех кернов. Максимальные концентрации приурочены к горизонту 0-1 см керна АМК-6948 и достигают 2326 ppm. Далее концентрации Mn резко снижаются и с глубины ниже 2 см варьируют в пределах 376-852 ppm. Значения фактора обогащения $\mathrm{Mn}$ находятся в диапазонах $0,70 \ldots 4,34$ и $0,80 \ldots 2,57$ для метановых и фоновых осадков соответственно. Содержание $\mathrm{Fe}_{2} \mathrm{O}_{3}$ изменяется в пределах от 4,2 до $6,2 \%$ в метановых осадках и от 8,6 до 9,2 \% в фоновых. Вертикальные профили показывают достаточно равномерное распределение $\mathrm{Fe}$ в трех изученных колонках и отсутствие тенденций к увеличению/снижению концентраций с глубиной. Средние значения фактора обогащения $\mathrm{Fe}$ составляют 1,09 для керна АМК-6027, 1,12 для керна АМК-6948 и 1,81 для керна АМК-6053. В целом среднее содержание $\mathrm{Fe}$ в метановых осадках $(3,54 \%)$ равно его среднему содержанию в осадочных породах континента $(3,5 \%$ [28]), при этом в фоновых осадках содержание $\mathrm{Fe}$ выше почти в 2 раза (табл. 1).
По концентрациям $\mathrm{Co}, \mathrm{Ni}, \mathrm{Cu}, \mathrm{Zn}, \mathrm{Cr}$ фоновые осадки сопоставимы осадочным породам континента, за исключением несколько пониженного содержания $\mathrm{Ni}$ и почти двукратного превышения по Zn. Вертикальное распределение этих элементов в колонке АМК-6053 относительно равномерное. Однако отмечается небольшой рост содержания Со с глубиной и единичные пики в профилях $\mathrm{Ni}$ и $\mathrm{Zn}$. В колонке АМК-6948 характер распределения $\mathrm{Co}, \mathrm{Ni}, \mathrm{Cu}, \mathrm{Zn}, \mathrm{Cr}$ по глубине в целом аналогичен фоновым осадкам, но при этом концентрации всех элементов ниже в 1,5-2 paза (табл. 1). В керне АМК-6027 профили $\mathrm{Ni}, \mathrm{Cu}, \mathrm{Cr}$ демонстрируют относительное превышение концентраций этих элементов в интервале $0-4 \mathrm{~cm}(875 \mathrm{ppm}$ для $\mathrm{Ni}\left(\mathrm{EF}_{\mathrm{Ni}}=22,2\right), 23,9 \mathrm{ppm}$ для $\mathrm{Cu}\left(\mathrm{EF}_{\mathrm{Cu}}=1,1\right)$ и $265,4 \mathrm{ppm}$ для $\left.\mathrm{Cr}\left(\mathrm{EF}_{\mathrm{Cr}}=3,6\right)\right)$. Средние же содержания $\mathrm{Co}, \mathrm{Cu}, \mathrm{Zn}, \mathrm{Cr}$ соизмеримы с колонкой АМК-6948.

Содержание Мо изменяется в диапазонах от 1,2 до $187,6 \mathrm{ppm}$ (среднее $=15,6 \mathrm{ppm}$ ) в метановых осадках и от 1,9 до 16,8 ppm (среднее=5,3 ppm) в фоновых. Профили вертикального распределения Мо показывают разные типы его поведения. В колонке АМК-6027 отмечается резкое снижение содержаний Мо с глубиной, но уже с горизонта $\sim 5$ см разброс значений не превышает 3 ppm. 
Таблица 1. Сводные данные о концентрациях отдельных химических элементов в кернах $А М К-$ 6027, $A M K-6948$ u $A M K-6053$

Table 1. Summary data for selected chemical elements of the cores $A M K-6027, A M K-6948$ and $A M K$ 6053

\begin{tabular}{|c|c|c|c|c|}
\hline \multirow[t]{2}{*}{ 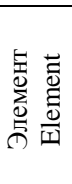 } & \multicolumn{2}{|c|}{$\begin{array}{c}\text { «Метановые» донные } \\
\text { осадки } \\
\text { Cold seep sediments }\end{array}$} & \multirow{2}{*}{$\begin{array}{c}\begin{array}{c}\text { Фоновые донные } \\
\text { осадки } \\
\text { Reference } \\
\text { sediments }\end{array} \\
\text { АМК-6053 }\end{array}$} & \multirow[t]{2}{*}{$\begin{array}{l}\text { Осадочная } \\
\text { кора* } \\
\text { Upper crust }\end{array}$} \\
\hline & АМК-6027 & АМК-6948 & & \\
\hline $\begin{array}{l}\text { TOC } \\
(\%)\end{array}$ & $\frac{0,32 \div 0,93}{0,53}$ & $\frac{0,42 \div 0,78}{0,56}$ & $\frac{1,02 \div 1,19}{1,09}$ & - \\
\hline $\begin{array}{l}\text { TIC } \\
(\%)\end{array}$ & $\frac{0,08 \div 0,19}{0,14}$ & $\frac{0,10 \div 0,23}{0,15}$ & $\frac{0,17 \div 0,21}{0,19}$ & - \\
\hline $\begin{array}{c}\mathrm{Fe}_{2} \mathrm{O}_{3} \\
(\%)\end{array}$ & $\frac{4,2 \div 5,9}{4,9}$ & $\frac{4,4 \div 6,2}{5,2}$ & $\frac{8,6 \div 9,2}{8,9}$ & $5,0^{* *}$ \\
\hline $\begin{array}{l}\mathrm{CaO} \\
(\%)\end{array}$ & $\frac{0,90 \div 1,11}{0,97}$ & $\frac{0,97 \div 1,85}{1,12}$ & $\frac{0,85 \div 1,01}{0,93}$ & $4,2^{* *}$ \\
\hline $\begin{array}{c}\mathrm{Mn} \\
(\mathrm{ppm})\end{array}$ & $\frac{473 \div 1335}{663}$ & $\frac{376 \div 2326}{785}$ & $\frac{429 \div 1380}{636}$ & 600 \\
\hline $\begin{array}{c}\mathrm{Co} \\
(\mathrm{ppm})\end{array}$ & $\frac{10,2 \div 15,2}{12,4}$ & $\frac{11,9 \div 18,3}{14}$ & $\frac{22,2 \div 29,0}{24,9}$ & 17 \\
\hline $\begin{array}{c}\mathrm{Ni} \\
(\mathrm{ppm})\end{array}$ & $\frac{12,2 \div 874}{134}$ & $\frac{5,2 \div 26,1}{13,4}$ & $\frac{12,2 \div 39,0}{29,3}$ & 44 \\
\hline $\begin{array}{c}\mathrm{Cu} \\
(\mathrm{ppm})\end{array}$ & $\frac{11,5 \div 23,9}{14,3}$ & $\frac{11,9 \div 18,0}{14,5}$ & $\frac{23,7 \div 26,5}{25,4}$ & 25 \\
\hline $\begin{array}{c}\mathrm{Zn} \\
(\mathrm{ppm})\end{array}$ & $\frac{64,6 \div 98,5}{78,3}$ & $\frac{72,7 \div 131}{87,6}$ & $\frac{113 \div 158}{127,6}$ & 71 \\
\hline $\begin{array}{c}\mathrm{Cr} \\
(\mathrm{ppm})\end{array}$ & $\frac{43,1 \div 265}{78,7}$ & $\frac{47,9 \div 73,2}{55,8}$ & $\frac{79,3 \div 95,0}{86,7}$ & 83 \\
\hline $\begin{array}{c}\mathrm{Ba} \\
(\mathrm{ppm})\end{array}$ & $\frac{568 \div 662}{608}$ & $\frac{539 \div 667}{603}$ & $\frac{413 \div 488}{449}$ & 550 \\
\hline $\begin{array}{c}\text { Mo } \\
\text { (ppm) }\end{array}$ & $\frac{5,35 \div 187,6}{31,1}$ & $\frac{1,16 \div 9,49}{4,97}$ & $\frac{1,87 \div 16,8}{5,25}$ & 1,5 \\
\hline $\begin{array}{c}\mathrm{U} \\
(\mathrm{ppm})\end{array}$ & $\frac{1,48 \div 2,30}{1,76}$ & $\frac{1,66 \div 3,24}{2,38}$ & $\frac{2,74 \div 3,43}{3,07}$ & 2,8 \\
\hline
\end{tabular}

Примечание/Note: в числителе указаны диапазоны кониентраций элементов (мин $\div$ макс), в знаменателе средние концентраџии в кернах/ranges of element concentrations (min-max) are in numerator, average concentrations in cores are in denominator; «-》- нem опубликованных данных/no data available; * - согласно данным (McLennan, 2001)/according to the data (McLennan, 2001); ** - пересчитано в оксидную форmy/converted to oxide form.

Для колонки АМК-6948 также характерно повышенное содержание Мо в верхнем горизонте $(5,4 \mathrm{ppm})$ и его уменьшение до горизонта 4 см, однако ниже этого горизонта наблюдается рост концентраций с глубиной. Профиль АМК-6053 демонстрирует минимальное содержание Мо в поверхностном горизонте и постепенный его рост по мере углубления. Концентрации $\mathrm{U}$ в метановых и фоновых осадках варьируют в пределах $1,48 \ldots 3,24 \mathrm{ppm}$ и $2,74 \ldots 3,43 \mathrm{ppm}$, соответственно, и увеличиваются с глубиной во всех трёх кернах. Средние концентрации U сопоставимы со средним содержанием в осадочных породах континентальной коры (табл. 1). В вертикальных профилях Ва отмечается схожесть его поведения как в метановых, так и в фоновых осадках, а именно широкий разброс концентраций в смежных горизонтах (до 90 ppm) и отсутствие их ярко выраженного увеличения или уменьшения по мере углубления (рис. 5). Одновременно с этим среднее содержание Ва в метановых осадках несколько выше, чем в фоновых, однако в обоих случаях оно соизмеримо со средним в осадочных породах континентов (табл. 1).

\section{Обсуждение результатов}

Содержание минерального углерода в метановых и фоновых осадках в исследованных кернах практически одинаково и в обоих случаях не превышает $0,23 \%$ (табл. 1). В отличие от колонки АМК-6053, колонки АМК-6027 и АМК-6948 показывают постепенное увеличение содержания ТIC с глубиной. Как известно, вследствие анаэробного окисления метана возникает избыточная щёлочность поровой воды, а также увеличивается содержание растворенного неорганического углерода в поровой воде, что способствует формированию карбонатов [29]. Однако процесс аутигенного карбонатообразования зависит от множества факторов, таких как: интенсивность потока метана, концентрации метана, скорость седиментации и др., и осаждение карбонатных минералов в метановых сипах происходит только при определенных физико-химических условиях [30-32]. Проведенные ранее исследования показывают наличие аутигенных карбонатных стяжений в виде $\mathrm{Mg}$-кальцита в поверхностных осадках рассматриваемого участка разгрузки метан-содержащих флюидов [33, 34]. Профили вертикального распределения ТIC и $\mathrm{CaO}$ в керне АМК-6948 в совокупности с их устойчивой корреляционной зависимостью $(\mathrm{R}=0,78)$ косвенно говорят о совместном нахождение этих элементов, предположительно, в форме карбонатных минералов и/или раковин моллюсков. Однако при подготовке проб в керне АМК-6948 карбонатных стяжений обнаружено не было, а визуально наблюдаемые раковины были извлечены. Пик в профилях ТІС и $\mathrm{CaO}$, приуроченный к горизонту 4-5 см, отражающий двукратное увеличение их концентраций, может объясняться наличием в пробе микрообломков раковин моллюсков, которые не были извлечены при подготовке проб ввиду их малых размеров. Рост концентраций ТІС и $\mathrm{CaO}$ с глубиной, вероятно, указывает на более глубокое положение зоны осаждения карбонатов на данном сиповом участке.

Содержание органического углерода в донных осадках зависит прежде всего от объема его потоков и от концентраций растворенного кислорода в водной толще [15]. Молекулярный состав органического вещества в данном районе [17] указывает на его преимущественно терригенное происхождение, а основными источниками служат речной сток (прежде всего p. Лена) и продукты разрушения берегового ледового комплекса. 

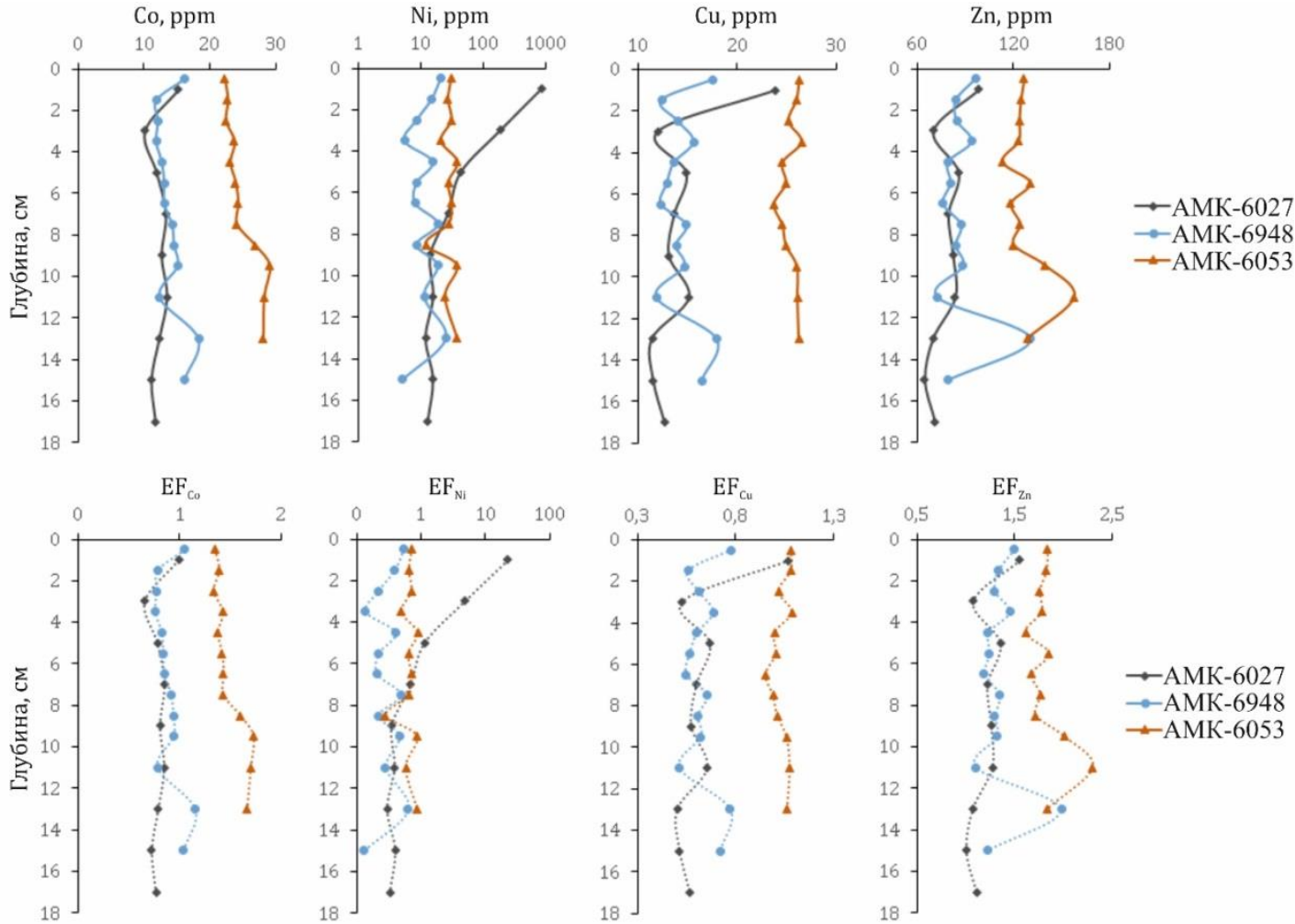

Pис. 4. Профили вертикального распределения концентраций (сверху) и факторов обогащения (снизу) Co, $\mathrm{Ni}$, Cu u Zn в кернах $A M K-6027, A M K-6948$ и $A M K-6053$

Fig. 4. Vertical distributions of concentrations (top) and enrichment factors (bottom) of $\mathrm{Co}, \mathrm{Ni}$, $\mathrm{Cu}$ and $\mathrm{Zn}$ in cores $\mathrm{AMK}$ 6027, $A M K-6948$ and $A M K-6053$
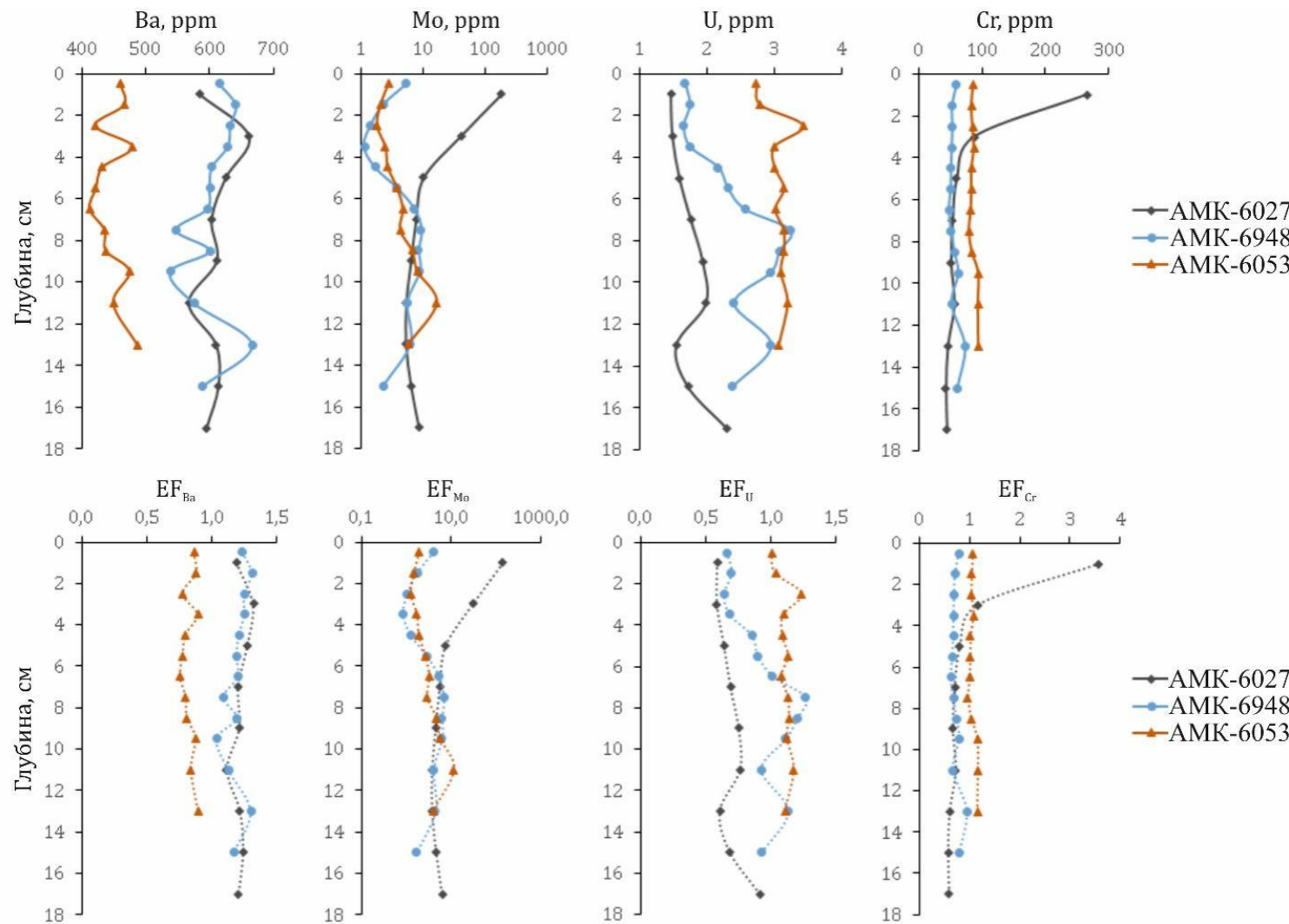

AMK-6948

$\simeq$-АMK-6053

Рис. 5. Профили вертикального распределения конщентраџий (сверху) и факторов обогащения (снизу) $\mathrm{Ba}, \mathrm{Mo}, \mathrm{U} u \mathrm{Cr}$ в кернах $A M K-6027, A M K-6948$ и $A M K-6053$

Fig. 5. Vertical distributions of concentrations (top) and enrichment factors (bottom) of $\mathrm{Ba}, \mathrm{Mo}, \mathrm{U}$ and $\mathrm{Cr}$ in cores $\mathrm{AMK}$ 6027, $A M K-6948$ and $A M K-6053$ 
По-видимому, разброс средних содержаний ТОС между двумя рассматриваемыми выборками проб является следствием неравномерного пространственного распределения потоков органического вещества на внешнем шельфе, что показано в работах $[17,35]$. В отличие от керна АМК-6053, где вертикальный профиль ТОС достаточно выдержан, за исключением приповерхностного слоя, керны АМК-6027 и АМК6948 показывают двукратное снижение концентраций органического углерода с глубиной, что вызвано его окислением в процессе диагенеза.

Как видно из рис. 3, вертикальное распределение Mn сопоставимо во всех колонках и характеризуется обогащением верхних 2-3 см. Как правило, в окислительной среде $\mathrm{Mn}$ осаждается в виде оксидов (например, $\mathrm{MnO}_{2}$ и $\left.\mathrm{MnO}(\mathrm{OH})\right)$, в восстановительной растворяется до ионов $\mathrm{Mn}^{2+}$ или $\mathrm{MnCl}^{2+}[36,37]$. Во время раннего диагенеза в поверхностном горизонте донных осадков образуются оксиды марганца, которые в дальнейшем захороняются и, оказываясь ниже зоны восстановления $\mathrm{Mn}$, мигрируют вверх и окисляются повторно [15]. В итоге мощность обогащённого марганцем слоя зависит от мощности аэробного слоя и в данном случае, предположительно, не превышает 2 см как в осадках метановых сипов, так и на фоновой станции.
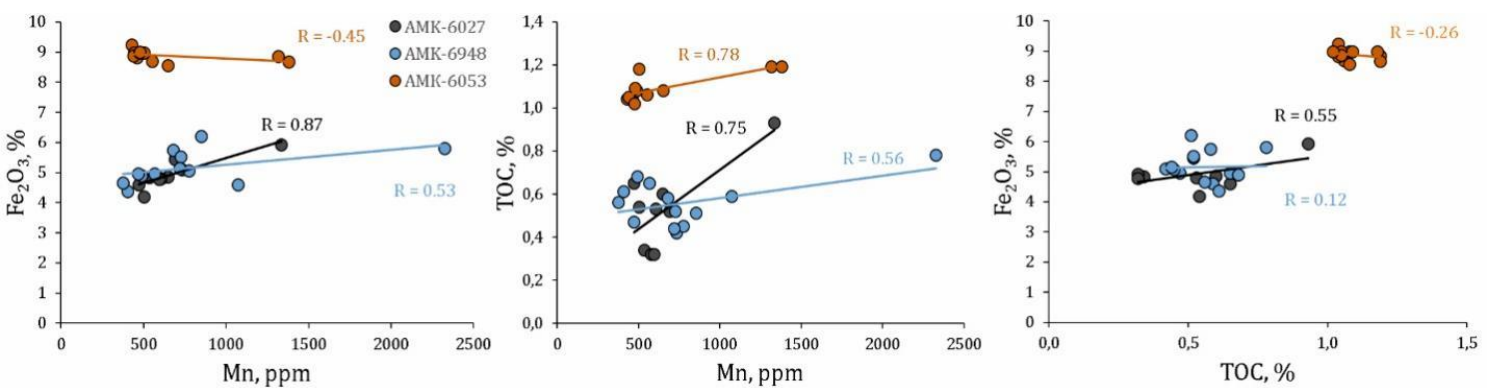

Pис. 6. Разброс содержаний $\mathrm{Mn}$ и $\mathrm{Fe}$ в зависимости от содержания общего органического углерода (ТОС) в кернах AMK-6027, $A M K-6948$ и $A M K-6053$

Fig. 6. Scatter plot of Mn and Fe content versus total organic carbon (TOC) content in cores AMK-6027, AMK-6948 and AMK-6053

Коэффициенты корреляции Мn с другими элементами (табл. 2) демонстрируют устойчивую (R>0,7) прямую связь с ТOC, $\mathrm{Fe}, \mathrm{Cr}, \mathrm{Co}, \mathrm{Ni}, \mathrm{Cu}, \mathrm{Zn}$ и Мо. Однако данные корреляционные связи наблюдается только в колонке АМК-6027 и отсутствуют в других колонках, за исключением связей между $\mathrm{Mn}$ и ТОС. Схожая ситуация наблюдается и с органическим углеродом, поскольку устойчивые связи между ТОС и рассматриваемыми элементами выявлены лишь в колонке AMK-6027. Известно, что перечисленные выше элементы активно адсорбируются из морской воды окислами и гидроокислами железа и марганца и, соответственно, высвобождаются в восстановительных условиях [38]. Часть высвобожденных ионов может быть адсорбирована органическим веществом или образовывать сульфидные формы. Также, благодаря восходящим потокам флюидов, растворенные элементы могут мигрировать из более глубоких горизонтов к поверхности, где, оказываясь в восстановительных условиях, вновь адсорбируются окислами и/или гидроокислами железа и марганца [38, 39]. Характерной особенностью поведения $\mathrm{Ni}, \mathrm{Cu}, \mathrm{Cr}$ является резкое скачкообразное увеличение их содержания в верхней части колонки АМК-6027, что также отражается в значениях факторов обогащения этих элементов (рис. 4, 5). Повидимому, данный рост концентраций является отражением изменения окислительно-восстановительного потенциала, сопровождающегося переходом $\mathrm{Ni}, \mathrm{Cu}, \mathrm{Cr}$ из растворенной формы в твердую. Высокие значения коэффициентов корреляции свидетельствуют о важной роли органического углерода, железа и марганца в поведении $\mathrm{Ni}, \mathrm{Cu}, \mathrm{Cr}$, что также отмечается другими ис- следователями [40-42]. В типичных морских условиях сильное обогащение никелем может указывать на (1) высокий поток органического вещества, которое активно сорбирует такие элементы, как $\mathrm{Ni}, \mathrm{Cu}, \mathrm{Zn}$ и др., образуя металлоорганические комплексы, и (2) восстановительные условия, способствующие осаждению $\mathrm{Ni}$ и $\mathrm{Cu}$ в отложениях [38]. Поскольку концентрации ТОС даже в поверхностном слое колонки АМК-6027 не превышают $1 \%$, можно предположить, что поступление металлорганических комплексов не является главной причиной обогащения осадков Ni. Bepoятнее всего, восходящий поток метан-содержащего флюида способствует миграции растворенных элементов ( $\mathrm{Ni}$ и, возможно, $\mathrm{Cu}$ ) из нижележащих горизонтов к поверхности, где при смене окислительновосстановительного потенциала происходит их осаждение. Сильные корреляционные связи $\mathrm{Cr}, \mathrm{Co}, \mathrm{Ni}, \mathrm{Cu}$, $\mathrm{Zn} \mathrm{c}$ органическим углеродом, железом и марганцем могут свидетельствовать о том, что ключевым механизмом, контролирующим осаждение данных элементов в поверхностном слое осадков, является их сорбция органическим веществом и оксигидроксидами $\mathrm{Fe}$ и Mn. Однако следует отметить, что в данном случае концентрации ТOC, Fe и $\mathrm{Mn}$ не являются определяющим фактором, т. к. содержание Мn сопоставимо во всех кернах, а содержание ТОС и $\mathrm{Fe}$ в керне АМК-6053 значительно выше (табл. 1, рис. 6). Предположительно, избирательное обогащения поверхностного слоя осадков некоторыми редокс-чувствительными элементами вызвано миграцией метан-содержащих флюидов, способствующих переносу элементов в растворенной форме из более глубоких горизонтов. 
Таблица 2. Коэффициенты корреляция между отдельными химическими элементами в кернах АМК-6027, АМК-6948 и AMK-6053

Table 2. Correlation coefficient matrix for selected chemical elements of the cores AMK-6027, AMK-6948 and AMK-6053

\begin{tabular}{|c|c|c|c|c|c|c|c|c|c|c|c|}
\hline & TOC & $\mathrm{Fe}$ & $\mathrm{Mn}$ & $\mathrm{Cr}$ & Co & $\mathrm{Ni}$ & $\mathrm{Cu}$ & $\mathrm{Zn}$ & $\mathrm{Ba}$ & Mo & $\mathrm{U}$ \\
\hline \multicolumn{12}{|c|}{$A M K-6027$} \\
\hline TOC & 1 & 0,55 & 0,75 & $\mathbf{0 , 8 3}$ & 0,61 & $\mathbf{0 , 8 1}$ & $\mathbf{0 , 8 8}$ & 0,89 & $-0,11$ & $\mathbf{0 , 8 0}$ & $-0,55$ \\
\hline $\mathrm{Fe}$ & & 1 & $\mathbf{0 , 8 7}$ & 0,67 & $\mathbf{0 , 9 4}$ & 0,65 & $\mathbf{0 , 8 3}$ & $\mathbf{0 , 7 6}$ & $-0,84$ & 0,65 & $-0,01$ \\
\hline $\mathrm{Mn}$ & & & 1 & 0,93 & $\mathbf{0 , 8 3}$ & 0,92 & 0,94 & 0,77 & $-0,52$ & 0,92 & $-0,24$ \\
\hline $\mathrm{Cr}$ & & & & 1 & 0,62 & 1 & 0,93 & $\mathbf{0 , 7 3}$ & $-0,19$ & 1 & $-0,49$ \\
\hline Co & & & & & 1 & 0,58 & 0,79 & $\mathbf{0 , 8 1}$ & $-0,79$ & 0,59 & $-0,06$ \\
\hline $\mathrm{Ni}$ & & & & & & 1 & 0,91 & 0,69 & $-0,16$ & 1 & $-0,49$ \\
\hline $\mathrm{Cu}$ & & & & & & & 1 & 0,91 & $-0,45$ & 0,91 & $-0,32$ \\
\hline $\mathrm{Zn}$ & & & & & & & & 1 & $-0,47$ & 0,69 & $-0,26$ \\
\hline $\mathrm{Ba}$ & & & & & & & & & 1 & 0,73 & $-0,45$ \\
\hline Mo & & & & & & & & & & 1 & $-0,48$ \\
\hline $\mathrm{U}$ & & & & & & & & & & & 1 \\
\hline \multicolumn{12}{|c|}{ AMK-6948 } \\
\hline TOC & 1 & 0,12 & 0,56 & $-0,33$ & $-0,25$ & 0,02 & 0,30 & 0,06 & 0,29 & $-0,34$ & $-0,75$ \\
\hline $\mathrm{Fe}$ & & 1 & 0,53 & 0,24 & 0,34 & 0,46 & 0,07 & $-0,07$ & $-0,64$ & 0,74 & 0,35 \\
\hline $\mathrm{Mn}$ & & & 1 & 0,17 & 0,39 & 0,52 & 0,46 & 0,14 & 0,00 & 0,22 & $-0,29$ \\
\hline $\mathrm{Cr}$ & & & & 1 & $\mathbf{0 , 9 3}$ & 0,75 & $\mathbf{0 , 7 0}$ & 0,79 & 0,26 & 0,40 & 0,54 \\
\hline Co & & & & & 1 & 0,68 & 0,74 & 0,64 & 0,18 & 0,43 & 0,49 \\
\hline $\mathrm{Ni}$ & & & & & & 1 & 0,49 & $\mathbf{0 , 7 2}$ & 0,17 & 0,55 & 0,30 \\
\hline $\mathrm{Cu}$ & & & & & & & 1 & 0,74 & 0,51 & $-0,13$ & $-0,10$ \\
\hline $\mathrm{Zn}$ & & & & & & & & 1 & 0,68 & 0,13 & 0,20 \\
\hline $\mathrm{Ba}$ & & & & & & & & & 1 & $-0,10$ & $-0,30$ \\
\hline Mo & & & & & & & & & & 1 & $\mathbf{0 , 7 9}$ \\
\hline $\mathrm{U}$ & & & & & & & & & & & 1 \\
\hline \multicolumn{12}{|c|}{$A M K-6053$} \\
\hline TOC & 1 & $-0,26$ & $\mathbf{0 , 7 8}$ & 0,15 & $-0,18$ & $-0,16$ & 0,57 & 0,41 & 0,33 & 0,19 & $-0,50$ \\
\hline $\mathrm{Fe}$ & & 1 & $-0,45$ & 0,08 & 0,44 & 0,27 & $-0,52$ & 0,20 & $-0,35$ & 0,41 & 0,09 \\
\hline $\mathrm{Mn}$ & & & 1 & $-0,13$ & $-0,49$ & $-0,03$ & 0,48 & $-0,06$ & 0,35 & $-0,34$ & $-0,74$ \\
\hline $\mathrm{Cr}$ & & & & 1 & 0,77 & 0,27 & 0,67 & 0,71 & 0,64 & 0,63 & 0,12 \\
\hline Co & & & & & 1 & 0,02 & 0,25 & 0,63 & 0,38 & $\mathbf{0 , 7 8}$ & 0,28 \\
\hline $\mathrm{Ni}$ & & & & & & 1 & $-0,01$ & $-0,02$ & 0,13 & $-0,15$ & $-0,09$ \\
\hline $\mathrm{Cu}$ & & & & & & & 1 & 0,49 & $\mathbf{0 , 8 7}$ & 0,19 & $-0,28$ \\
\hline $\mathrm{Zn}$ & & & & & & & & 1 & 0,29 & 0,85 & 0,21 \\
\hline $\mathrm{Ba}$ & & & & & & & & & 1 & 0,91 & $-0,42$ \\
\hline Mo & & & & & & & & & & 1 & 0,28 \\
\hline $\mathrm{U}$ & & & & & & & & & & & 1 \\
\hline
\end{tabular}

Примечание/Note: полужирным выделены значения коэффициента коррелячии, показывающие устойчивые прямые и обратные связи/values of correlation factor, indicating stable direct and indirect links are in bold.

Значение $\mathrm{EF}$ молибдена $\left(\mathrm{EF}_{\mathrm{Mo}}=139,9\right)$ для горизонта 0-2 см колонки АМК-6027 указывает на высокую степень его аутигенного обогащения. Ниже горизонта 4

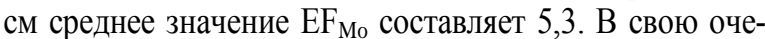
редь, коэффициенты корреляция Мо с $\mathrm{Mn}(\mathrm{R}=0,92)$ и $\mathrm{TOC}(\mathrm{R}=0,8)$ подразумевают сильную связь молибдена c гидроокислами марганца и органическим углеродом в поверхностном аэробном слое осадка. В колонке АМК-6948 также отмечается обогащение молибдена в поверхностном слое, но в значительно меньшей степени $\left(\mathrm{EF}_{\mathrm{Mo}}=4\right)$. С глубиной значения $\mathrm{EF}_{\mathrm{Mo}}$ возрастают до 6,9 (горизонт 7-8 см) при среднем по всей колонке 3,6. При этом корреляционный анализ показывает отсутствие связей Мо с ТОС и Мn и наличие устойчивой прямой связи $\mathrm{Mo} \mathrm{c} \mathrm{Fe}(\mathrm{R}=0,74)$. Данные корреляционные связи в совокупности с характером вертикального распределения Мо (рис. 5) отражают как минимум 2 разных механизма его накопления. В процессе раннего диагенеза осаждение растворенного Мо может происходить как в окислительных, так и в восстановительных условиях [43-45]. В случае с окислительными условиями наиболее известным и хорошо изученным механизмом является адсорбция Мо окислами и гидроокислами марганца [41]. Кроме этого, молибден мо- жет активно захватываться органическим веществом, в частности гуминовыми кислотами $[46,47]$. Точный механизм, с помощью которого растворенный Мо переходит в твердую фазу в восстановительных условиях, остается предметом обсуждения [48, 49]. Принято считать, что при высоких концентрациях сероводорода МоO42- трансформируется в тетратиомолибдат, а затем накапливается в Fe-Mo-S фазах $[47,50]$. Таким образом, сильное обогащение молибдена в аэробном слое керна АМК-6027, по-видимому, связано с его осаждением на поверхности окислов и гидроокислов марганца, а также с сорбцией органическим веществом. В нижней части керна АМК-6027, а также в керне АМК-6948 переход растворенного Мо в твердую форму, вероятно, связан с образованием сульфидных фаз в условиях насыщения $\mathrm{H} 2 \mathrm{~S}$.

\section{Выводы}

Было исследовано поведение углерода, железа, марганца и отдельных редокс-чувствительных микроэлементов в донных осадках внешнего шельфа моря Лаптевых, подверженных просачиванию метансодержащих флюидов. Анализ полученных результатов позволяет сделать следующие выводы: 
1) миграция метан-содержащих флюидов не оказывает существенного влияния на содержание органического углерода в донных осадках на количественном уровне. Разные концентрации ТОС в метановых и фоновых осадках могут объясняться спецификой пространственного распределения потоков органического вещества в исследуемом районе. Рост содержания ТІС с глубиной в метановых осадках является следствием анаэробного окисления метана, способствующего продуцированию растворенного неорганического углерода, что ранее отмечалось другими исследователями;

2) на участках разгрузки метана поверхностный слой донных осадков характеризуется обогащением Мо, $\mathrm{Ni}$ и $\mathrm{Cr}$. Сорбция этих элементов органическим веществом и окислами/гидрокислами Fe-Mn, повидимому, является ключевым механизмом, контролирующим осаждение $\mathrm{Mo}, \mathrm{Ni}$ и $\mathrm{Cr}$, на что указывают тесные корреляционные связи. Однако необходимо учитывать, что небольшой объём выборок проб по кернам $(\mathrm{n}=9 . .14)$ и узкий диапазон

\section{СПИСОК ЛИТЕРАТУРЫ}

1. Early diagenesis and accumulation of redox-sensitive elements in East Siberian Arctic Shelves / L. Li, Y. Liu, X. Wang, L. Hu, G. Yang, H. Wang, A.A. Bosin, A.S. Astakhov, X. Shi // Marine Geology. - 2020. - V. 429. - 106309.

2. IPCC Special report on the ocean and cryosphere in a changing climate / Eds. H.-O. Pörtner, D.C. Roberts, V. Masson-Delmotte, P. Zhai, M. Tignor, E. Poloczanska, K. Mintenbeck, A. Alegría, M. Nicolai, A. Okem, J. Petzold, B. Rama, N.M. Weyer // IPCC. 2019. URL: https://www.ipcc.ch/site/assets/uploads/sites/3/2019/ 11/07_SROCC_Ch03_FINAL.pdf (дата обращения 15.09.2021).

3. Increased fluxes of shelf-derived materials to the Central Arctic Ocean / L.E. Kipp, M.A. Charette, W.S. Moore, P.B. Henderson, I.G. Rigor // Science Advances. - 2018. - V. 4 - Article № eaao 1302.

4. Redox conditions and authigenic mineralization related to cold seeps in central Guaymas Basin, Gulf of California / F. NúñezUseche, C. Canet, V. Liebetrau, T.P. Puig, A.C. Ponciano, P. Alfonso, C. Berndt, C. Hensen, C. Mortera-Gutierrez, A.A. Rodríguez-Díaz // Marine Petroleum Geology. - 2018. V. $95 .-$ P. $1-15$.

5. The formation of authigenic carbonates at a methane seep site in the northern part of the Laptev sea / A. Ruban, M. Rudmin O. Dudarev, A. Mazurov // Minerals. - 2020. - V. 10. - Article № 948.

6. Methane-consuming archaebacteria in marine sediments / K.-U. Hinrichs, J.M. Hayes, S.P. Sylva, P.G. Brewer, E.F. DeLong // Nature. - 1999. - V. 398. - P. 802-805.

7. Geochemistry of cold seepage-impacted sediments: per-ascensum or per-descensum trace metal enrichment? / N. Tribovillard, E.A. du Châtelet, A. Gay, F. Barbecot, P. Sansjofre, J.L. Potdevin // Chemical Geology. - 2013. - V. 340. - P. 1-12.

8. Gas seeps at the edge of the gas hydrate stability zone on Brazil's continental margin / M. Ketzer, D. Praeg, M.A.G. Pivel, A.H. Augustin, L.F. Rodrigues, A.R. Viana, J.A. Cupertino // Geosciences. - 2019. - V. 9. - Article № 193.

9. Impact of anaerobic oxidation of methane on the geochemical cycle of redox-sensitive elements at cold-seep sites of the northern South China Sea / Y. Hu, D. Feng, Q. Liang, Z. Xia, L. Chen, D. Chen // Deep-Sea Research II. - 2015. - V. 122. - P. 84-94.

10. Early diagenesis of redox-sensitive trace metals in the Peru upwelling area - response to ENSO-related oxygen fluctuations in the water column / F. Scholz, C. Hensen, A. Noffke, A. Rohde, V. Liebetrau, K. Wallmann // Geochimica et Cosmochimica Acta. - 2011. - V. 75. - P. 7257-7276.

11. Evidence of intense methane seepages from molybdenum enrichments in gas hydrate-bearing sediments of the northern South China Sea / F. Chen, Y. Hu, D. Feng, X. Zhang, S. Cheng, J. Cao, H. Lu, D. Chen // Chemical Geology. - 2016. - V. 443. - P. 173-181. концентраций TOC и Fе могут значимо влиять на результаты корреляционного анализа;

3) обогащение поверхностного слоя осадков некоторыми редокс-чувствительными элементами характерно только для одного из участков разгрузки метана. Вероятно, это вызвано разными физикохимическими параметрами миграции метансодержащих флюидов (прежде всего интенсивностью потока и концентрациями $\mathrm{CH}_{4}$ ), способствующих переносу элементов в растворенной форме из более глубоких горизонтов.

Работа выполнена при финансовой поддержке гранта Президента РФ (аналитические исследования проведены в рамках реализаџии проекта № $М К-1774.2021 .1 .5)$. Часть фактического материал для проведения исследований была получена в ходе экспедиции на НИС «Академик Мстислав Келдыш» (рейс 73, 2018 г.), организованной при поддержке Правительства Российской Федерации (грант № 14.Z.50.31.0012). И.П. Семилетов и О.В. Дударев выражают благодарность Российскому научному фонду (проект № 21-77-30001).

12. Dickens G.R. Sulfate profiles and barium fronts in sediment on the Blake Ridge: present and past methane fluxes through a large as hydrate reservoir // Geochimica et Cosmochimica Acta. - 2001. V. 65. - P. 529-543.

13. New insights into cerium anomalies and mechanisms of trace metal enrichment in authigenic carbonate from hydrocarbon seeps / Y. Hu, D. Feng, J. Peckmann, H.H. Roberts, D. Chen // Chemical Geology. - 2014. - V. 381. - P. 55-66.

14. Contribution of cold seep barite to the barium geochemical budget of a marginal basin / E.L. McQuay, M.E. Torres, R.W. Collier, C.A. Huh, J. McManus // Deep Sea Research Part I: Oceanographic Research Papers. - 2008. - V. 55. - P. 801-811.

15. Geochemistry of deep sea sediments at cold seep sites in the Nankai Trough: insights into the effect of anaerobic oxidation of methane / H. Sato, K.I. Hayashi, Y. Ogawa, K. Kawamura // Marine Geology. - 2012. - V. 323-325. - P. 47-55.

16. Geochemical signatures of intense episodic anaerobic oxidation of methane in near-surface sediments of a recently discovered cold seep (Kveithola trough, NW Barents Sea) / M. Bazzaro, N. Ogrinc, F. Relitti, R.G. Lucchi, M. Giani, G. Adami, E. Pavoni, C. De Vittor // Marine Geology. - 2020. - V. 425. - 106189.

17. Contrasting composition of terrigenous organic matter in the dissolved, particulate and sedimentary organic carbon pools on the outer East Siberian Arctic Shelf / J.A. Salvadó, T. Tesi, M. Sundbom, E. Karlsson, M. Krusä, I.P. Semiletov, E. Panova, Ö. Gustafsson // Biogeosciences. - 2016. - V. 13. - P. 6121-6138.

18. Razumov S.O., Grigoriev M.N. Modeling of coastal dynamics of the Laptev and East Siberian seas in the second half of Holocene // Earth's Cryosphere. - 2017. - V. 21. - P. 36-45.

19. Methane seeps on the outer shelf of the Laptev Sea: characteristic features, structural control, and benthic fauna / B. Baranov, S. Galkin, A. Vedenin, K. Dozorova, A. Gebruk, M. Flint // GeoMarine Letters. - 2020. - V. 40. - P. 541-557.

20. Mechanisms responsible for gas emission and underwater permafrost degradation on Laptev Sea shelf / L.I. Lobkovskiy, S.L. Nikiforov, N.N. Dmitrevskiy, N.V. Libina, I.P. Semiletov, R.A. Ananiev, A.A. Meluzov, A.G. Roslyakov // Oceanology. 2015. - V. 55. - P. 312-320.

21. The East Siberian Arctic Shelf: towards further assessment of permafrost-related methane fluxes and role of sea ice / N. Shakhova, I. Semiletov, V. Sergienko, L. Lobkovsky, V. Yusupov, A. Salyuk, A. Salomatin, D. Chernykh, D. Kosmach, G. Panteleev, D. Nicolsky, V. Samarkin, S. Joye, A. Charkin, O. Dudarev, A. Meluzov, Ö. Gustafsson // Philosophical Transactions of the Royal Society A: Mathematical, Physical and Engineering Sciences. - 2015. - V. 373. - 20140451.

22. Source apportionment of methane escaping the subsea permafrost system in the outer Eurasian Arctic Shelf / J. Steinbach, 
H. Holmstrand, K. Shcherbakova, D. Kosmach, V. Brüchert, N. Shakhova, A. Salyuk, C.J. Sapart, D. Chernykh, R. Noormets, I. Semiletov, Ö. Gustafsson // Proceedings of the National Academy of Sciences. - 2021. - V. 118. - № 10. - e2019672118.

23. Драчев С.С. О тектонике фундамента шельфа моря Лаптевых // Геотектоника. - 2002. - № 6. - Р. 60-76.

24. Sekretov S.B. Structure and tectonic evolution of the Southern Eurasia Basin, Arctic Ocean // Tectonophysics. - 2002. - V. 351. P. 193-243.

25. Деградация подводной мерзлоты и разрушение гидратов шельфа морей Восточной Арктики как возможная причина «метановой катастрофы»: некоторые результаты комплексных исследований 2011 года / В.И. Сергиенко, Л.И. Лобковский, И.П. Семилетов, О.В. Дударев, Н.Н. Дмитревский, Н.Е. Шахова, Н.Н. Романовский, Д.А. Космач, Д.Н. Никольский, С.Л. Никифоров, А.С. Саломатин, Р.А. Ананьев, А.Г. Росляков, А.Н. Салюк, В.В. Карнаух, Д.Б. Черных, В.Е. Тумской, В.И. Юсупов, А.В. Куриленко, Е.М. Чувилин, Б.А. Буханов Доклады Академии наук. - 2012. - Т. 446. - № 3. - С. 330-335.

26. Thermokarst and land-ocean interactions, Laptev Sea region, Russia / N.N. Romanovskii, H.W. Hubberten, A.V. Gavrilov, V.E. Tumskoy, G.S. Tipenko, M.N. Grigoriev, C. Siegert // Permafrost and Periglacial Processes. - 2000. - V. 11. - P. 137-152.

27. Shakhova N., Semiletov I. Methane release and coastal environment in the East Siberian Arctic shelf // Journal of Marine Systems. - 2007. - V. 66. - P. 227-243.

28. McLennan S.M. Relationships between the trace element composition of sedimentary rocks and upper continental crust // Geochemistry, Geophys. Geosystems. - 2001. - V. 2. 2000GC000109.

29. Methane-related authigenic carbonates of Eastern Mediterranean Sea mud volcanoes and their possible relation to gas hydrate destabilisation / G. Aloisi, C. Pierre, J.M. Rouchy, J.P. Foucher, J. Woodside // Earth and Planetary Science Letters. - 2000. V. 184. - P. 321-338

30. $\mathrm{Sr} / \mathrm{Ca}$ and $\mathrm{Mg} / \mathrm{Ca}$ ratios in Niger Delta sediments: implications for authigenic carbonate genesis in cold seep environments / G. Bayon, C. Pierre, J. Etoubleau, M. Voisset, E. Cauquil, T. Marsset, N. Sultan, E. Le Drezen, Y. Fouquet // Marine Geology. - 2007. V. 241. - P. 93-109.

31. Using sediment geochemistry to infer temporal variation of methane flux at a cold seep in the South China Sea / N. Li, D. Feng, L. Chen, H. Wang, D. Chen // Marine Petroleum Geology. - 2016. V. 77. - P. 835-845.

32. Luff R., Wallmann K., Aloisi G. Numerical modeling of carbonate crust formation at cold vent sites: significance for fluid and methane budgets and chemosynthetic biological communities // Earth and Planetary Science Letters. - 2004. - V. 221. - P. 337-353.

33. Methane-derived authigenic carbonates on the seafloor of the Laptev Sea shelf / M.D. Kravchishina, A.Y. Lein, M.V. Flint, B.V. Baranov, A.Y. Miroshnikov, E.O. Dubinina, O.M. Dara, A.G. Boev, A.S. Savvichev // Frontiers in Marine Science. 2021. - V. 8. - 690304.

34. Аутигенные минералы в донных осадках сиповых областей моря Лаптевых / А.С. Рубан, М.А. Рудмин, Е.В. Гершелис, А.А. Леонов, А.К. Мазуров, О.В. Дударев, И.П. Семилетов // Известия Томского политехнического университета. Инжиниринг георесурсов. - 2020. - Т. 331. - № 7. - С. 24-36.

35. Carbon geochemistry of plankton-dominated samples in the Laptev and East Siberian shelves: contrasts in suspended particle composition / T. Tesi, M.C. Geibel, C. Pearce, E. Panova, J.E. Vonk, E. Karlsson, A.J. Salvado, M. Krusä, L. Bröder, C. Humborg, I. Semiletov, Ö. Gustafsson // Ocean Science. 2017. - V. 13. - P. 735-748.
36. Early oxidation of organic matter in pelagic sediments of the eastern equatorial Atlantic: suboxic diagenesis / P.N. Froelich, G.P. Klinkhammer, M.L. Bender, N.A. Luedtke, G.R. Heath, D. Cullen, P. Dauphin, D. Hammond, B. Hartman, V. Maynard // Geochimica et Cosmochimica Acta. - 1979. - V. 43. - P. 1075-1090

37. Bruland K.W. Trace metals in sea-water // Chemical Oceanographic / Eds. J.P. Riley, R. Chester. - London: Academic Press, 1983. - V. 8. - P. 157-220.

38. Trace metals as paleoredox and paleoproductivity proxies: an update / N. Tribovillard, T.J. Algeo, T. Lyons, A. Riboulleau // Chemical Geology. - 2006. - V. 232. - P. 12-32.

39. Geochemistry and mineralogy of sediments and authigenic carbonates from the Malta Plateau, Strait of Sicily (Central Mediterranean): relationships with mud/fluid release from a mud volcano system / M. Cangemi, R. Di Leonardo, A. Bellanca, A. Cundy, R. Neri, M. Angelone // Chemical Geology. - 2010. V. 276. - P. 294-308.

40. Enrichment of Trace Metals (V, $\mathrm{Cu}, \mathrm{Co}, \mathrm{Ni}$, and Mo) in Arctic Sediments - From Siberian Arctic Shelves to the Basin / L. Li, X. Wang, Y. Ren, H. Su, L. Hu, G. Yang, Z. Li, A.A. Bosin, A.S. Astakhov, J. Chen, Y. Liu, X. Shi / Journal of Geophysical Research: Oceans. - 2021. - V. 126. - e2020JC016960.

41. Sundby B., Martinez P., Gobeil C. Comparative geochemistry of cadmium, rhenium, uranium, and molybdenum in continental margin sediments // Geochimica et Cosmochimica Acta. - 2004. V. 68. - P. 2485-2493.

42. Formation of authigenic carbonates at a methane seep site in the middle Okinawa Trough, East China Sea / M. Wang, Q. Li, F. Cai, J. Liang, G. Yan, Z. Wang, Y. Sun, D. Luo, G. Dong, Y. Cao // Journal of Asian Earth Sciences. - 2019. - V. 185. - 104028.

43. Calvert S.E., Pedersen T.F. Geochemistry of recent oxic and anoxic marine sediments: implications for the geological record // Marine Geology. - 1993. - V. 113. - P. 67-88.

44. The distribution of $\mathrm{Mo}, \mathrm{U}$, and $\mathrm{Cd}$ in relation to major redox species in muddy sediments of the Bay of Biscay / G. Chaillou, P. Anschutz, G. Lavaux, J. Schafer, G. Blanc // Marine Chemistry. - 2002. - V. 80. - P. 41-59.

45. Diagenesis of oxyanions ( $\mathrm{V}, \mathrm{U}, \mathrm{Re}$, and $\mathrm{Mo})$ in pore waters and sediments from a continental margin / J.L. Morford, S.R. Emerson, E.J. Breckel, S.H. Kim // Geochimica et Cosmochimica Acta. 2005. - V. 69. - P. 5021-5032.

46. Algeo T.J., Lyons T.W. Mo-total organic carbon covariation in modern anoxic marine environments: implications for analysis of paleoredox and paleohydrographic conditions // Paleoceanography. - 2006. - V. 21. - PA1016.

47. Mechanism of molybdenum removal from the sea and its concentration in black shales: EXAFS evidence / G.R. Helz, C.V. Miller, J.M. Charnock, J.F.W. Mosselmans, R.A.D. Pattrick, C.D. Garner, D.J. Vaughan / Geochimica et Cosmochimica Acta. 1996. - V. 60. - P. 3631-3642

48. Does pyrite act as an important host for molybdenum in modern and ancient euxinic sediments? / A. Chappaz, T.W. Lyons, D.D. Gregory, C.T. Reinhard, B.C. Gill, C. Li, R.R. Large // Geochimica et Cosmochimica Acta. - 2014. - V. 126. - P. 112-122.

49. Early diagenesis and trace element accumulation in North American Arctic margin sediments / Z.Z.A. Kuzyk, C. Gobeil, M.A. Goñi, R.W. Macdonald // Geochimica et Cosmochimica Acta. - 2017. - V. 203. - P. 175-200.

50. Multiple sulfur isotope constraints on sulfate-driven anaerobic oxidation of methane: evidence from authigenic pyrite in seepage areas of the South China Sea / Z. Lin, X. Sun, H. Strauss, Y. Lu, J. Gong, L. Xu, H. Lu, B.M.A. Teichert, J. Peckmann // Geochimica et Cosmochimica Acta. - 2017. - V. 211. - P. 153-173.

Поступила 24.11.2021 2.

\section{Информация об авторах}

$\boldsymbol{P} \boldsymbol{y} \boldsymbol{a} \boldsymbol{A} \boldsymbol{A} \boldsymbol{C}$., кандидат геолого-минералогических наук, доцент отделения геологии Инженерной школы природных ресурсов Национального исследовательского Томского политехнического университета.

Pудмин М.A., кандидат геолого-минералогических наук, доцент отделения геологии Инженерной школы природных ресурсов Национального исследовательского Томского политехнического университета. 
Мазуров A.K., доктор геолого-минералогических наук, профессор отделения геологии Инженерной школы природных ресурсов Национального исследовательского Томского политехнического университета.

Милевский Я.В., студент отделения геологии Инженерной школы природных ресурсов Национального исследовательского Томского политехнического университета.

Семилетов И.П., член-корреспондент РАН, доктор географических наук, заведующий лабораторией арктических исследований Тихоокеанского океанологического института им. В.И. Ильичева ДВО РАН; профессор отделения геологии Инженерной школы природных ресурсов Национального исследовательского Томского политехнического университета.

Гершелис E.B., кандидат геолого-минералогических наук, доцент отделения геологии Инженерной школы природных ресурсов Национального исследовательского Томского политехнического университета.

Дударев О.В., доктор геолого-минералогических наук, главный научный сотрудник лаборатории арктических исследований Тихоокеанского океанологического института им. В.И. Ильичева ДВО РАН. 
UDC 550.42; 550.47

\section{GEOCHEMICAL SPECIFIC OF SEDIMENTS AT METHANE COLD SEEP SITE ON THE LAPTEV SEA OUTER SHELF}

\author{
Alexey S. Ruban ${ }^{1}$, \\ ruban@tpu.ru
}

\section{Maxim A. Rudmin ${ }^{1}$,} rudminma@tpu.ru

Yakov V. Milevsky',
yvm16@tpu.ru

Alexey K. Mazurov' ${ }^{1}$ akm@tpu.ru

1 National Research Tomsk Polytechnic University, 30, Lenin avenue, Tomsk, 634050, Russia.

2 Pacific Oceanological Institute FEB RAS,

43, Baltiyskaya street, Vladivostok, 690041, Russia.

\author{
Igor P. Semiletov2,1, \\ ipsemiletov@alaska.edu
}

Elena V. Gershelis ${ }^{1}$, elenapanova@tpu.ru

Oleg V. Dudarev², dudarev@poi.dvo.ru

Relevance. A specific feature of the Laptev Sea shelf is the sites of discharge of methane-containing fluids from the surface of the seabed into the water column (methane cold seeps). The key biogeochemical processes occurring during methane migration through the sedimentary environment are anaerobic oxidation of methane and bacterial sulfate reduction. The activity of these processes encourages a change in the redox conditions of sedimentation, which affects the biogeochemical cycles of some redox-sensitive elements.

The aim of the research is to study the influence of methane-containing fluids on the geochemical cycles of iron, carbon and some redoxsensitive elements.

Objects. The data of the concentrations of carbon, iron, and some of redox-sensitive elements ( $\mathrm{Mn}, \mathrm{Co}, \mathrm{Ni}, \mathrm{Cu}, \mathrm{Zn}, \mathrm{Cr}, \mathrm{Ba}, \mathrm{Mo}, \mathrm{U})$ in three bottom sediment cores sampled on the outer shelf of the Laptev Sea were analyzed. Two of the three cores were obtained at methane cold seep sites and were considered as sediments subject to anaerobic methane oxidation.

Methods: pyrolysis (Rock-Eval 6 Turbo, Vinci Technologies), X-Ray analysis (HORIBA X-Ray Analytical Microscope XGT 7200), Inductively coupled plasma mass spectrometry (ICP-MS, ELAN DRC-e).

Results. TOC and Fe contents in sediments do not reflect the impact of anaerobic oxidation on their geochemical cycles and controlled by the specifics of the spatial distribution of sedimentary material. In all the studied cores, there are elevated Mn concentrations confined to the surface layer of sediments. At methane cold seep sites, the surface layer of bottom sediments is characterized by enrichment in Mo, Ni and $\mathrm{Cr}$. The selective enrichment of the surface layer of sediments with some redox-sensitive elements can be caused by the migration of methane-containing fluids, which facilitate the transport of elements in dissolved form from deeper horizons. The sorption of these elements by organic matter and Fe-Mn oxihydroxides appears to be the key mechanism controlling the deposition of $\mathrm{Mo}, \mathrm{Ni}$, and $\mathrm{Cr}$.

\section{Key words:}

Geochemistry, methane seeps, anaerobic methane oxidation, Laptev Sea.

The research was supported by the grant from the President of the Russian Federation to support young Russian scientists (laboratory investigations were carried out within the framework of the project no. MK-1774.2021.1.5). Part of material for research was obtained during expedition on the $R / V$ «Akademik Mstislav Keldysh» (cruise no. 73, 2018), organized with the support of the Russian Federation Government (grant no. 14.Z.50.31.0012). I.P. Semiletov and O.V. Dudarev thank the Russian Science Foundation (project No. 21-77-30001).

\section{REFERENCES}

1. Li L., Liu Y., Wang X., Hu L., Yang G., Wang H., Bosin A.A., Astakhov A.S., Shi X.. Early diagenesis and accumulation of redox-sensitive elements in East Siberian Arctic Shelves. Marine Geology, 2020, vol. 429, 106309.

2. IPCC special report on the ocean and cryosphere in a changing climate. Eds. H.-O. Pörtner, D.C. Roberts, V. Masson-Delmotte, P. Zhai, M. Tignor, E. Poloczanska, K. Mintenbeck, A. Alegría, M. Nicolai, A. Okem, J. Petzold, B. Rama, N.M. Weyer. IPCC 2019. Available at: https://www.ipcc.ch/site/assets/uploads/sites/3/2019/ 11/07 SROCC Ch03 FINAL.pdf (accessed 15 September 2021)

3. Kipp L.E., Charette M.A., Moore W.S., Henderson P.B., Rigor I.G. Increased fluxes of shelf-derived meterials to the Central Arctic Ocean. Science Advances, 2018, 4, eaao 1302.

4. Núñez-Useche F., Canet C., Liebetrau V., Puig T.P., Ponciano A.C., Alfonso P., Berndt C., Hensen C., Mortera-Gutierrez C.,
Rodríguez-Díaz A.A. Redox conditions and authigenic mineralization related to cold seeps in central Guaymas Basin, Gulf of California. Marine Petroleum Geology, 2018, vol. 95, pp. 1-15.

5. Ruban A., Rudmin M., Dudarev O., Mazurov A. The formation of authigenic carbonates at a methane seep site in the northern part of the Laptev Sea. Minerals, 2020, vol. 10, article no. 948.

6. Hinrichs K.-U., Hayes J.M., Sylva S.P., Brewer P.G., DeLong E.F. Methane-consuming archaebacteria in marine sediments. Nature, 1999, vol. 398, pp. 802-805.

7. Tribovillard N., du Châtelet E.A., Gay A., Barbecot F., Sansjofre P., Potdevin J.L. Geochemistry of cold seepageimpacted sediments: Per-ascensum or per-descensum trace metal enrichment? Chemical Geology, 2013, vol. 340, pp. 1-12.

8. Ketzer M., Praeg D., Pivel M.A.G., Augustin A.H., Rodrigues L.F., Viana A.R., Cupertino J.A. Gas seeps at the edge of the gas 
hydrate stability zone on Brazil's continental margin. Geosciences, 2019, vol. 9, article no. 193.

9. Hu Y., Feng D., Liang Q., Xia Z., Chen L., Chen D. Impact of anaerobic oxidation of methane on the geochemical cycle of redox-sensitive elements at cold-seep sites of the northern South China Sea. Deep-Sea Research II, 2015, vol. 122, pp. 84-94.

10. Scholz F., Hensen C., Noffke A., Rohde A., Liebetrau V., Wallmann K. Early diagenesis of redox-sensitive trace metals in the Peru upwelling area - response to ENSO-related oxygen fluctuations in the water column. Geochimica et Cosmochimica Acta, 2011, vol. 75, pp. 7257-7276.

11. Chen F., Hu Y., Feng D., Zhang X., Cheng S., Cao J., Lu H., Chen D. Evidence of intense methane seepages from molybdenum enrichments in gas hydrate-bearing sediments of the northern South China Sea. Chemical Geology, 2016, vol. 443, pp. 173-181.

12. Dickens G.R. Sulfate profiles and barium fronts in sediment on the Blake Ridge: Present and past methane fluxes through a large as hydrate reservoir. Geochimica et Cosmochimica Acta, 2001, vol. 65 , pp. 529-543.

13. Hu Y., Feng D., Peckmann J., Roberts H.H., Chen D. New insights into cerium anomalies and mechanisms of trace metal enrichment in authigenic carbonate from hydrocarbon seeps. Chemical Geology, 2014, vol. 381, pp. 55-66.

14. McQuay E.L., Torres M.E., Collier R.W., Huh C.A., McManus J. Contribution of cold seep barite to the barium geochemical budget of a marginal basin. Deep Sea Research Part I: Oceanographic Research Papers, 2008, vol. 55, pp. 801-811.

15. Sato H., Hayashi K.I., Ogawa Y., Kawamura K. Geochemistry of deep sea sediments at cold seep sites in the Nankai Trough: insights into the effect of anaerobic oxidation of methane. Marine Geology, 2012, vol. 323-325, pp. 47-55.

16. Bazzaro M., Ogrinc N., Relitti F., Lucchi R.G., Giani M., Adami G., Pavoni E., De Vittor C. Geochemical signatures of intense episodic anaerobic oxidation of methane in near-surface sediments of a recently discovered cold seep (Kveithola trough, NW Barents Sea). Marine Geology, 2020, vol. 425, 106189.

17. Salvadó J.A., Tesi T., Sundbom M., Karlsson E., Krusä M., Semiletov I.P., Panova E., Gustafsson Ö. Contrasting composition of terrigenous organic matter in the dissolved, particulate and sedimentary organic carbon pools on the outer East Siberian Arctic Shelf. Biogeosciences, 2016, vol. 13, pp. 6121-6138.

18. Razumov S.O., Grigoriev M.N. Modeling of coastal dynamics of the Laptev and East Siberian seas in the second half of Holocene. Earth's Cryosphere, 2017, vol. 21, pp. 36-45.

19. Baranov B., Galkin S., Vedenin A., Dozorova K., Gebruk A., Flin M. Methane seeps on the outer shelf of the Laptev Sea characteristic features, structural control, and benthic fauna. GeoMarine Letters, 2020, vol. 40, pp. 541-557.

20. Lobkovskiy L.I., Nikiforov S.L., Dmitrevskiy N.N., Libina N.V. Semiletov I.P., Ananiev R.A., Meluzov A.A., Roslyakov A.G. Mechanisms Responsible for Gas Emission and Underwater Permafrost Degradation on Laptev Sea Shelf. Oceanology, 2015, vol. 55 , pp. 312-320.

21. Shakhova N., Semiletov I., Sergienko V., Lobkovsky L., Yusupov V., Salyuk A., Salomatin A., Chernykh D., Kosmach D., Panteleev G., Nicolsky D., Samarkin V., Joye S., Charkin A., Dudarev O., Meluzov A., Gustafsson Ö. The East Siberian Arctic Shelf: towards further assessment of permafrost-related methane fluxes and role of sea ice. Philosophical Transactions of the Royal Society A: Mathematical, Physical and Engineering Sciences, 2015, vol. 373, 20140451.

22. Steinbach J., Holmstrand H., Shcherbakova K., Kosmach D., Brüchert V., Shakhova N., Salyuk A., Sapart C.J., Chernykh D., Noormets R., Semiletov I., Gustafsson Ö. Source apportionment of methane escaping the subsea permafrost system in the outer Eurasian Arctic Shelf. Proceedings of the National Academy of Sciences, 2021, vol. 118, no. 10, e2019672118.

23. Drachev S.S. On the basement tectonics of the Laptev Sea shelf Geotectonics, 2002, vol. 36, pp. 483-497.

24. Sekretov S.B. Structure and tectonic evolution of the Southern Eurasia Basin, Arctic Ocean. Tectonophysics, 2002, vol. 351, pp. 193-243.

25. Sergienko V.I., Lobkovskii L.I., Semiletov I.P., Dudarev O.V., Dmitrievskii N.N., Shakhova N.E., Romanovskii N.N., Kosmach D.A., Nikol'Skii D.N., Nikiforov S.I., Salomatin A.S.,
Anan'ev R.A., Roslyakov A.G., Salyuk A.N., Karnaukh V.V., Chernykh D.V., Tumskoi V.E., Yusupov V.I., Kurilenko A.V., Chuvilin E.M., Bukhanov B.A. The degradation of submarine permafrost and the destruction of hydrates on the shelf of east arctic seas as a potential cause of the Methane Catastrophe: Some results of integrated studies in 2011. Doklady Earth Sciences, 2012, vol. 446, pp. 1132-1137.

26. Romanovskii N.N., Hubberten H.W., Gavrilov A.V., Tumskoy V.E., Tipenko G.S., Grigoriev M.N., Siegert C. Thermokarst and land-ocean interactions, Laptev Sea region, Russia. Permafrost and Periglacial Processes, 2000, vol. 11, pp. 137-152.

27. Shakhova N., Semiletov I. Methane release and coastal environment in the East Siberian Arctic shelf. Journal of Marine Systems, 2007, vol. 66, pp. 227-243.

28. McLennan S.M. Relationships between the trace element composition of sedimentary rocks and upper continental crust. Geochemistry, Geophys. Geosystems, 2001, vol. 2, 2000GC000109.

29. Aloisi G., Pierre C., Rouchy J.M., Foucher JP., Woodside J. Methane-related authigenic carbonates of Eastern Mediterranean Sea mud volcanoes and their possible relation to gas hydrate destabilisation. Earth and Planetary Science Letters, 2000, vol. 184, pp. 321-338.

30. Bayon G., Pierre C., Etoubleau J., Voisset M., Cauquil E., Marsset T., Sultan N., Le Drezen E., Fouquet $\mathrm{Y}$. $\mathrm{Sr} / \mathrm{Ca}$ and $\mathrm{Mg} / \mathrm{Ca}$ ratios in Niger Delta sediments: Implications for authigenic carbonate genesis in cold seep environments. Marine Geology, 2007, vol. 241, pp. 93-109.

31. Li N., Feng D., Chen L., Wang H., Chen D. Using sediment geochemistry to infer temporal variation of methane flux at a cold seep in the South China Sea. Marine Petroleum Geology, 2016, vol. 77, pp. 835-845.

32. Luff R., Wallmann K., Aloisi G. Numerical modeling of carbonate crust formation at cold vent sites: significance for fluid and methane budgets and chemosynthetic biological communities. Earth and Planetary Science Letters, 2004, vol. 221, pp. 337-353.

33. Kravchishina M.D., Lein A.Y., Flint M.V., Baranov B.V., Miroshnikov A.Y., Dubinina E.O., Dara O.M., Boev A.G., Savvichev A.S. Methane-derived authigenic carbonates on the seafloor of the Laptev Sea shelf. Frontiers in Marine Science, 2021, vol. 8, 690304

34. Ruban A.S., Rudmin M.A., Gershelis E.V., Leonov A.A., Mazurov A.K., Dudarev O.V., Semiletov I.P. Authigenic minerals in the bottom sediments from seeps of the Laptev Sea. Bulletin of the Tomsk Polytechnic University. Geo Assets Engineering, 2020, vol. 331, no. 7, pp. 24-36. In Rus.

35. Tesi T., Geibel M.C., Pearce C., Panova E., Vonk J.E., Karlsson E. Salvado A.J., Krusä M., Bröder L., Humborg C., Semiletov I., Gustafsson Ö. Carbon geochemistry of plankton-dominated samples in the Laptev and East Siberian shelves: contrasts in suspended particle composition. Ocean Science, 2017, vol. 13, pp. 735-748.

36. Froelich P.N., Klinkhammer G.P., Bender M.L., Luedtke N.A., Heath G.R., Cullen D., Dauphin P., Hammond D., Hartman B., Maynard V. Early oxidation of organic matter in pelagic sediments of the eastern equatorial Atlantic: suboxic diagenesis. Geochimica et Cosmochimica Acta, 1979, vol. 43, pp. 1075-1090.

37. Bruland K.W. Trace metals in sea-water. Chemical Oceanographic. Eds. J.P. Riley, R. Chester. London, Academic Press, 1983. Vol. 8, pp. 157-220.

38. Tribovillard N., Algeo T.J., Lyons T., Riboulleau A. Trace metals as paleoredox and paleoproductivity proxies: an update. Chemical Geology, 2006, vol. 232, pp. 12-32.

39. Cangemi M., Di Leonardo R., Bellanca A., Cundy A., Neri R., Angelone M. Geochemistry and mineralogy of sediments and authigenic carbonates from the Malta Plateau, Strait of Sicily (Central Mediterranean): relationships with mud/fluid release from a mud volcano system. Chemical Geology, 2010, vol. 276, pp. 294-308.

40. Li L., Wang X., Ren Y., Su H., Hu L., Yang G., Li Z., Bosin A.A., Astakhov A.S., Chen J., Liu Y., Shi X. Enrichment of trace metals $(\mathrm{V}, \mathrm{Cu}, \mathrm{Co}, \mathrm{Ni}$, and $\mathrm{Mo}$ ) in Arctic sediments -from Siberian Arctic shelves to the basin. Journal of Geophysical Research: Oceans, 2021, vol. 126, e2020JC016960.

41. Sundby B., Martinez P., Gobeil C. Comparative geochemistry of cadmium, rhenium, uranium, and molybdenum in continental 
margin sediments. Geochimica et Cosmochimica Acta, 2004 vol. 68, pp. 2485-2493.

42. Wang M., Li Q., Cai F., Liang J., Yan G., Wang Z., Sun Y., Luo D., Dong G., Cao Y. Formation of authigenic carbonates at a methane seep site in the middle Okinawa Trough, East China Sea. Journal of Asian Earth Sciences, 2019, vol. 185, 104028.

43. Calvert S.E., Pedersen T.F. Geochemistry of recent oxic and anoxic marine sediments: Implications for the geological record. Marine Geology, 1993, vol. 113, pp. 67-88.

44. Chaillou G., Anschutz P., Lavaux G., Schafer J. and Blanc G. The distribution of $\mathrm{Mo}, \mathrm{U}$, and $\mathrm{Cd}$ in relation to major redox species in muddy sediments of the Bay of Biscay. Marine Chemistry, 2002, vol. 80, pp. 41-59.

45. Morford J.L., Emerson S.R., Breckel E.J. and Kim S.H. Diagenesis of oxyanions (V, U, Re, and Mo) in pore waters and sediments from a continental margin. Geochimica et Cosmochimica Acta, 2005, vol. 69, pp. 5021-5032.

46. Algeo T.J., Lyons T.W. Mo-total organic carbon covariation in modern anoxic marine environments: Implications for analysis of paleoredox and paleohydrographic conditions. Paleoceanography, 2006, vol. 21, PA1016.

\section{Information about the authors}

Alexey S. Ruban, Cand. Sc., associate professor, National Research Tomsk Polytechnic University.

Maxim A. Rudmin, Cand. Sc., associate professor, National Research Tomsk Polytechnic University.

Yakov V. Milevsky, student, National Research Tomsk Polytechnic University.

Alexey K. Mazurov, Dr. Sc., professor, National Research Tomsk Polytechnic University.

Igor P. Semiletov, Dr. Sc., corresponding member of the Russian Academy of Sciences, head of the Laboratory, Pacific Oceanological Institute FEB RAS; professor, National Research Tomsk Polytechnic University.

Elena V. Gershelis, Cand. Sc., associate professor, National Research Tomsk Polytechnic University.

Oleg V. Dudarev, Dr. Sc., chief researcher, Pacific Oceanological Institute FEB RAS. 